\title{
Influence of position of methoxy groups in Zn-methoxyphenylporphyrins
}

\author{
BISHNU PRASAD BORAH and JAGANNATH BHUYAN*(i) \\ Department of Chemistry, North Eastern Regional Institute of Science and Technology (NERIST), Nirjuli, \\ Arunachal Pradesh 791 109, India \\ E-mail: jnb@nerist.ac.in
}

MS received 12 February 2018; revised 17 June 2018; accepted 27 June 2018; published online 10 August 2018

\begin{abstract}
The crystal structure of the compound, $\mathrm{Zn}$ (II) 5,10,15,20-tetrakis(meta-methoxyphenyl)porphyrin chloroform trisolvate, $\left[\mathrm{ZnT}\left(m-\mathrm{OCH}_{3}\right) \mathrm{PP}\right] \cdot 3 \mathrm{CHCl}_{3} 1$ reveals that it forms a weak one-dimensional chain structure through interaction between $\mathrm{Zn}$ of porphyrin and the oxygen atom of the methoxy group of a neighbouring porphyrin. The zinc-oxygen interaction observed in compound $\mathbf{1}$ is compared with $\mathrm{Zn}$ (II) 5,10,15,20-tetrakis(para-methoxyphenyl)porphyrin [ZnT( $p$-OCH $\left.\mathrm{OCP}_{3}\right) \mathbf{2}$ and $\mathrm{Zn}$ (II) 5,10,15,20-tetrakis(3,4,5tri-methoxyphenyl)porphyrin $\left[\mathrm{ZnT}\left(3,4,5-\right.\right.$ triOCH$\left.\left._{3}\right) \mathrm{PP}\right] \mathbf{3}$ to understand the preferred methoxy-position of interaction. The strength of the non-covalent zinc-oxygen (methoxy group of a neighboring porphyrin) interaction in compound $\mathbf{1}$ is in between that of similar interactions observed in compounds $\mathbf{2}$ and $\mathbf{3}$. The Mulliken charge analysis using theoretical calculation at the DFT level shows that the meta-methoxy oxygen has a higher probability of binding to the metal than the para-methoxy oxygen. In the presence of nucleophiles, the formation of one-dimensional chain structure stops due to the binding of the nucleophiles to the metal zinc. The photoluminescence and differential scanning calorimetric studies were also performed for compound 1.
\end{abstract}

Keywords. Porphyrin; coordination polymer; zinc; UV-Visible spectra; X-ray crystallography.

\section{Introduction}

In the last few decades, non-covalent interaction have been of great interest in inorganic chemistry. ${ }^{1-4}$ Porphyrins are very attractive molecules for studying noncovalent interactions and have been used to construct supramolecular assemblies due to their macrocyclic structure. ${ }^{5}$ In addition to that, porphyrin non-covalent interactions have significant interest in various biological processes because it provides specificity and flexibility which is required for the biological processes such electron transfer, oxygen transport, etc. ${ }^{6-10}$ On the other hand, a coordination polymer is formed when a ligand bridges between metal ions, and each metal is bonded to more than one linker (ligand) to form an extended arrangement of metal ions. Porphyrin, the broadly found biological ligand is a beautiful building block for the formation of coordination polymer due to its rigid structure and the metallation site. ${ }^{11,12}$ Coordination polymers of porphyrin molecules have demand due to their bio-mimetic model of electron transfer in photosynthesis, catalysis and as sensors. ${ }^{13}$ The 5,10,15,20-tetra(4-pyridyl)porphyrin $\left(\mathrm{H}_{2} \mathrm{TPyP}\right), 5,10,15,20$-tetrakis(4-carboxyphenyl)porphyrin $\left(\mathrm{H}_{6} \mathrm{TCPP}\right)$ and $\mathrm{Zn}(\mathrm{II}) 1,2$-bis(meso octaethylporphyrin)ethane are the most common porphyrin ligands used for formation of coordination polymers ${ }^{14}$ and metal-organic frameworks due to their additional metal binding site at pyridyl and carboxylate groups. ${ }^{15} \mathrm{Zn}$ 5,10,15,20-tetra(4-pyridyl)porphyrin is reported to form J-type aggregation through $\mathrm{Zn}-\mathrm{N}$ axial coordination. ${ }^{16}$ There are others reports of porphyrin coordination polymers and metal organic framework due to its bridging ligand capability. ${ }^{17}$ Coordination polymers and metal-organic frameworks with different carboxylates and metal ions are known. ${ }^{18}$ The zinc(II) 5,15-di-(2methoxymethylphenyl)-porphyrin forms three dimensional coordination polymer through the interaction of methoxy-oxygen atoms of one porphyrin peripheries to the metal centers of two neighbouring identical

\footnotetext{
*For correspondence

Electronic supplementary material: The online version of this article (https://doi.org/10.1007/s12039-018-1516-2) contains supplementary material, which is available to authorized users.
} 

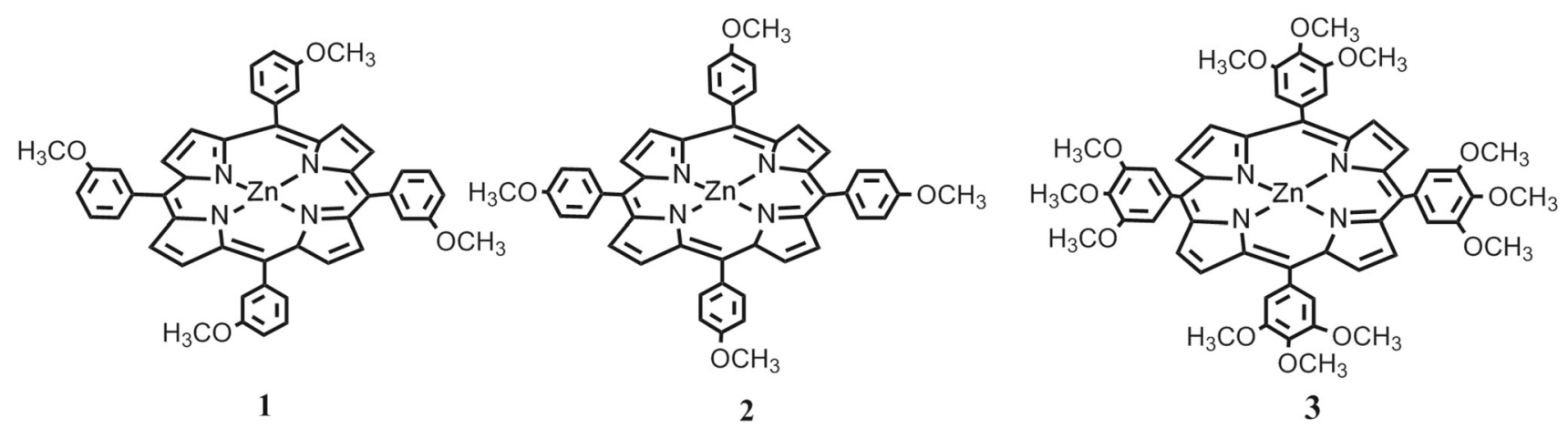

Figure 1. The chemical drawings of compound 1, 2 and $\mathbf{3 .}$

porphyrins. ${ }^{19}$ An another porphyrin $\mathrm{Zn}(\mathrm{II}) 1$,2-bis (meso-octaethylporphyrin)ethane is reported to form an one-dimensional coordination polymer with $\mathrm{N}, \mathrm{N}$ bispyridine-4-yl-methylene ethylenediamine by forming a dimer and the same forms a sandwich structure with 1,2-diaminobenzene. ${ }^{20}$

We have recently shown that the 5,10,15,20-tetrakis (3,4,5-tri-methoxyphenyl)porphyrinato, $\{\mathrm{T}(3,4,5$-triO$\left.\left.\mathrm{CH}_{3}\right) \mathrm{PP}\right\}$ is a beautiful ligand to form diverse coordination polymers. ${ }^{21,22}$ This ligand has three methoxy groups in the peripheral phenyl rings at 3, 4 and 5 position and can form 1D coordination polymer through binding of different methoxy groups to a neighbouring metal of the adjacent porphyrin. We observed the formation of $1 \mathrm{D}$ coordination polymer of $\operatorname{MgT}(3,4,5$ triOCH$\left.H_{3}\right) \mathrm{PP}$ and $\mathrm{ZnT}\left(3,4,5\right.$-triOCH $\left.\mathrm{H}_{3}\right) \mathrm{PP}$ through metaoxygen (oxygen atom from the $m$-methoxy group of an adjacent porphyrin)-metal bonds. ${ }^{21}$ To understand whether the $m$-methoxy group is only special position to form a 1D coordination polymer, here in this work we studied the zinc-oxygen interaction in zinc(II) $(5,10,15,20$-tetrakis(3-methoxyphenyl)) porphyrin, [ZnT(3-OCH $) \mathrm{PP}]$ (1) and compared with $\mathrm{Zn}$ (II) 5,10,15,20-tetrakis(4-methoxyphenyl)porphyrin $\left[\mathrm{ZnT}\left(4-\mathrm{OCH}_{3}\right) \mathrm{PP}\right] \mathbf{2}^{23}$ and $\mathrm{Zn}(\mathrm{II})$ 5,10,15,20tetrakis-(3,4,5-tri-methoxyphenyl)porphyrin $[\mathrm{ZnT}(3,4$, 5-triOCH$\left.\left.{ }_{3}\right) \mathrm{PP}\right] \mathbf{3}$ (Figure 1). The crystal structure of 1 reveals that it has an interaction similar to $\mathrm{MgT}\left(3,4,5\right.$-triOCH$\left.{ }_{3}\right) \mathrm{PP}$ and $\mathrm{ZnT}\left(3,4,5-\right.$ triOCH$\left._{3}\right)$ $\mathrm{PP}$ between trans metal oxygen (oxygen atom from the $m$-methoxy group of an adjacent porphyrin) bonds. The aggregation mode of porphyrins determines several biological properties of porphyrin. ${ }^{24}$ We have studied the interaction of $\mathbf{1}$ with various nucleophiles to understand the stability of the chain structure and its aggregation. The differential scanning calorimeter (DSC) studies for compound $\mathbf{1}$ was performed to understand the thermal properties. The thermal stability of 5,10,15,20-tetrakis-(4-methoxyphenyl)porphyrin, $\left(\mathrm{T}\left(4-\mathrm{OCH}_{3}\right) \mathrm{PP}\right)$ was reported to higher than $5,10,15$, 20-tetrakis(3-methoxyphenyl) porphyrin, $\left(\mathrm{T}\left(3-\mathrm{OCH}_{3}\right)\right.$ PP). ${ }^{25}$

\section{Experimental}

\subsection{Materials and methods}

Solvents like dichloromethane, hexane, chloroform and $N, N$ dimethylformamide were purchased from Merck Life Science Private Ltd. 3-Methoxybenzaldehyde and pyrrole were purchased from Spectrochem Private Ltd.

\subsection{Physical Measurements}

Electronic absorption spectral measurements for both solid and solution samples were recorded in a Perkin-Elmer (Lamda 35) spectrophotometer. Luminescence spectral measurements were carried out using an Aligant Cary Eclipse Fluorescence Spectrophotometer. Elemental analysis for carbon, hydrogen and nitrogen were checked with Leco CHNOS 948 carbon hydrogen nitrogen oxygen and sulfur determination. Infrared spectra were recorded on a Shimadzu FT-IR spectrophotometer as pressed $\mathrm{KBr}$ disks in the IR region. DSC measurement was carried out with Shimadzu DSC-60 at a scan rate of $5^{\circ} \mathrm{C} / \mathrm{min}$.

\section{$2.3 X$-ray structural analysis}

The diffracted crystal was glued to a glass fiber and mounted on BRUKER SMART APEX diffractometer. The instrument was equipped with CCD area detector and data were collected using graphite-monochromated Mo $\mathrm{K} \alpha$ radiation $(\lambda=0.71073 \AA)$ at room temperature $(293 \mathrm{~K})$. The crystallographic data, conditions retained for the intensity data collection and some features of the structure refinements are listed Table S1 in Supplementary Information. All empirical absorption corrections were applied using the SADABS program. All data were collected with SMART 5.628 (BRUKER, 2003), and were integrated with the BRUKER SAINT program. The crystal structure was solved using SIR97 and refined using SHELXL-97. The space group of the compound was obtained based on the lack of systematic absence 
and intensity statistics. Full matrix least squares/difference Fourier cycles were performed which located the nonhydrogen atoms. All non-hydrogen atoms were refined with anisotropic displacement parameters. The structural figures were drawn with the Ortex 2 program. ${ }^{26}$

\subsection{Synthesis of ligand 5,10,15,20-tetrakis- (meta-methoxyphenyl)porphyrin, $\mathrm{H}_{2} \mathrm{~T}\left(\mathrm{~m}-\mathrm{OCH}_{3}\right) \mathrm{PP}$}

The ligand 5,10,15,20-tetrakis(3-methoxyoxyphenyl) porphyrin, $\mathrm{H}_{2} \mathrm{~T}\left(3-\mathrm{OCH}_{3}\right) \mathrm{PP}$ was synthesized by refluxing 7.5 $\mathrm{mL}$ pyrrole $(144 \mathrm{mmol})$ and $13.13 \mathrm{~mL} m$-anisaldehyde (144 $\mathrm{mmol}$ ) in $250 \mathrm{~mL}$ propionic acid following the reported procedure. $^{27}$ The yield of the compound was found as $20 \%$. The molecular formula of the ligand is $\mathrm{C}_{48} \mathrm{H}_{38} \mathrm{~N}_{4} \mathrm{O}_{4}$. Molecular weight 734 . UV/Visible bands are at $\lambda_{\max } / \mathrm{nm}$ (in $\left.\mathrm{CHCl}_{3}, 10^{-6} \mathrm{M}\right) 419\left(560000 \mathrm{Lmol}^{-1} \mathrm{~cm}^{-1}\right), 514$ (23000 $\mathrm{Lmol}^{-1} \mathrm{~cm}^{-1}$ ), 553 (7000 $\left.\mathrm{Lmol}^{-1} \mathrm{~cm}^{-1}\right), 590$ (5000 $\mathrm{Lmol}^{-1}$ $\mathrm{cm}^{-1}$ ) and $646\left(4200 \mathrm{Lmol}^{-1} \mathrm{~cm}^{-1}\right)$, respectively. IR analysis gave characteristics peaks at 3603, 3402, 2939, 1805, $1705,1589,1465,1165,1041,979,910,794,726,648,462$ $\mathrm{cm}^{-1}$, respectively.

\subsection{Synthesis of compound [ $\left.\mathrm{ZnT}\left(\mathrm{m}-\mathrm{OCH}_{3}\right) \mathrm{PP}\right]$. $3 \mathrm{CHCl}_{3} \mathbf{1}$}

A sample of $0.6 \mathrm{~g}(0.81 \mathrm{mmol})$ of the porphyrin $\mathrm{H}_{2} \mathrm{~T}(\mathrm{~m}$ $\mathrm{OCH}_{3}$ )PP was taken in a $50 \mathrm{~mL}$ of DMF in a round bottom flask followed by addition of $0.255 \mathrm{~g}$ of $\mathrm{ZnCl}_{2}(1.875 \mathrm{mmol})$ and was refluxed for $1 \mathrm{~h}$. The mixture was dried in a water bath to remove the solvent. The dried compound was dissolved in dichloromethane then filtered and evaporated. The compound 1 was finally isolated and purified by column chromatography using dichloromethane and hexane as solvent. The compound was re-crystallized using chloroform and petroleum-ether mixture. The yield of the compound 1 was 95\%. Molecular Formula: $\mathrm{C}_{51} \mathrm{H}_{39} \mathrm{Cl}_{9} \mathrm{~N}_{4} \mathrm{O}_{4} \mathrm{Zn}$; Molecular Weight 1155.5; UV/Vis (in $\mathrm{CHCl}_{3}$ ) $\lambda_{\max } / \mathrm{nm}(\varepsilon): 423\left(380000 \mathrm{Lmol}^{-1} \mathrm{~cm}^{-1}\right.$ ), 550 (15000 $\mathrm{Lmol}^{-1} \mathrm{~cm}^{-1}$ ), 593 (5000 $\mathrm{Lmol}^{-1} \mathrm{~cm}^{-1}$ ); IR analysis gave characteristics peaks at 2928, 2840, 1649, 1587, 1470, 1328, 1273, 1173, 1007, 926, 790, 704, $667 \mathrm{~cm}^{-1}$, respectively.

\section{Result and Discussion}

\subsection{Crystal structure of compound $\left[\mathrm{ZnT}\left(\mathrm{m}-\mathrm{OCH}_{3}\right) \mathrm{PP}\right] \cdot 3 \mathrm{CHCl}_{3} \mathbf{1}$}

The complex 1 crystallizes in a triclinic system with P-1 space group. The crystallographic data for the compound $\mathbf{1}$ is given in Table $\mathrm{S} 1$ in Supplementary Information. The crystal structure of complex $\mathbf{1}$ consists of two unique $\mathrm{Zn}$ (II) ions, $\mathrm{Zn} 1$ and $\mathrm{Zn} 2$ situated in special positions, and two crystallographically independent molecules of the porphyrin ligand tetra

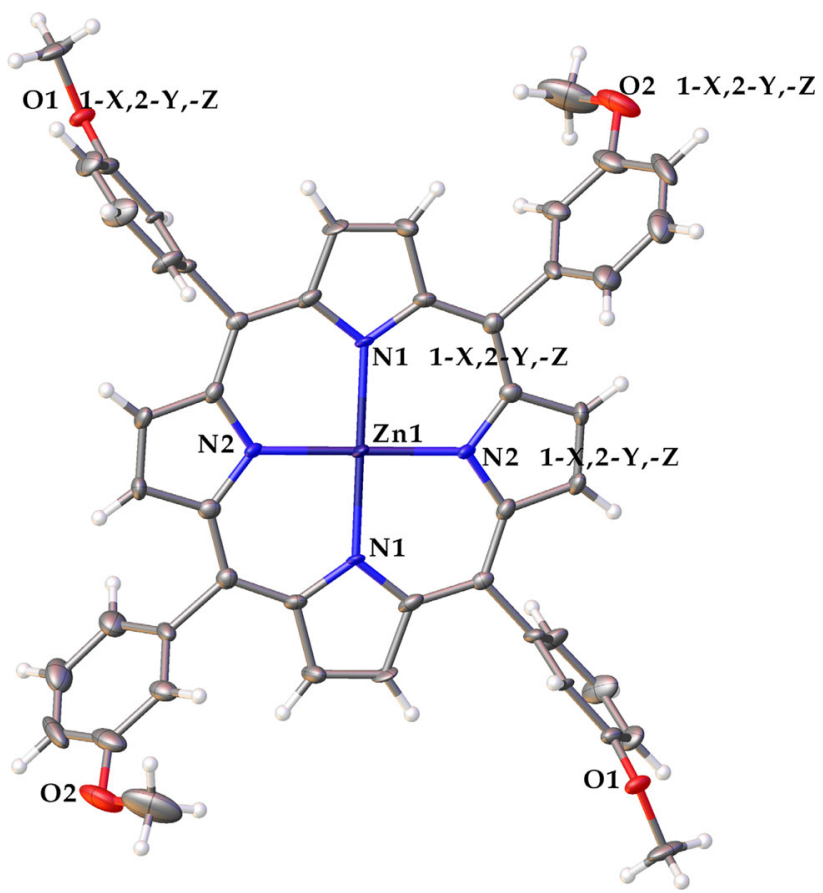

Figure 2. The perspective view of compound $\mathbf{1}$.

meta-methoxyphenylporphyrin (first porphyrin ligand is with pyrrole nitrogens N1N2 and second is N3N4) and three chloroform solvent molecules. Figure 2 shows the perspective view of the chemical surroundings of one of the unique $\mathrm{Zn}(\mathrm{Zn} 1)$ ions. The perspective view of compound 1 with the both $\mathrm{Zn}$ (II) ions and symmetry codes of nitrogen and oxygen atoms is shown in Figure $\mathrm{S} 1$ in Supplementary Information. The metal zinc is in the plane of the porphyrin ring. The $\mathrm{Zn}-\mathrm{N}(\mathrm{py})$ bond length was found to be in the range from $2.028 \AA$ to $2.055 \AA$. The metal $\mathrm{Zn} 1$ makes two long bonds at $2.674 \AA$ with O4 of meta methoxy group of the adjacent porphyrin (both are $\mathrm{O} 4$ and are trans because $\mathrm{Zn} 1$ is on an inversion centre) while $\mathrm{Zn} 2$ makes two long bonds at $2.604 \AA$ with meta methoxy group of the adjacent porphyrin (both are O1). The extended structure with this weak interaction of the compound $\mathbf{1}$ is shown in Figure 3 and Figure S2 (Supplementary Information). The Zn1$\mathrm{O} 4$ and $\mathrm{Zn} 2-\mathrm{O} 1$ distances in compound $\mathbf{1}$ is too long to be considered as true $\mathrm{Zn}-\mathrm{O}$ bonds; hence compound $\mathbf{1}$ is not a coordination polymer but forms a weak onedimensional chain structure through this bond (Figure $\mathrm{S} 2$ ). The $\mathrm{Zn}-\mathrm{O}$ bond distance (2.604 and $2.674 \AA$ ) in complex $\mathbf{1}$ is slightly longer than reported the longest six coordinate $\mathrm{Zn}-\mathrm{O}$ bond distance of $\mathrm{Zn}(\mathrm{THF})_{2}$ complex. $^{28}$

We recently reported the formation of $1 \mathrm{D}$ coordination polymer of $\mathrm{ZnT}(3,4,5$-triOCH 3$) \mathrm{PP}$ and $\mathrm{MgT}(3,4$, 5-triOCH $\mathrm{H}_{3}$ ) PP through meta-oxygen (oxygen atom from 


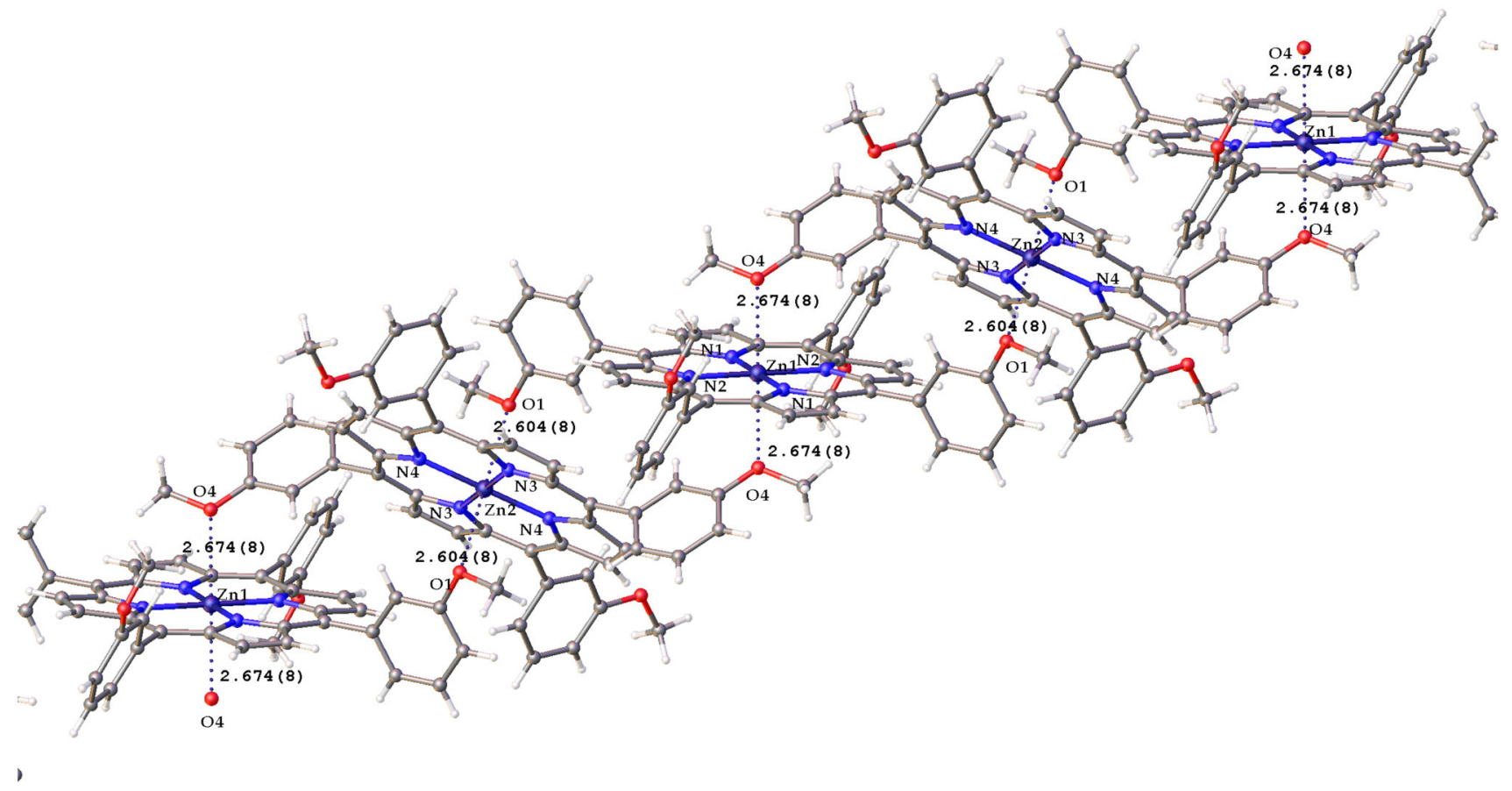

Figure 3. Illustration of the one-dimensional infinite chain due to the weak zinc (metal) -oxygen (methoxy) interaction.

the $m$-methoxy group of an adjacent porphyrin) -metal bonds. ${ }^{21}$ We have compared the $\mathrm{Zn}-\mathrm{O}$ bond of complex 1 of with reported crystallographic data of zinc(II) (5,10,15,20-tetrakis(4-methoxyphenyl))porphyrin [ZnT $\left.\left(p-\mathrm{OCH}_{3}\right) \mathrm{PP}\right] 2$ and zinc(II) $(5,10,15,20$-tetrakis $(3,4,5$ tri-methoxyphenyl))porphyrin, $\left[\mathrm{ZnT}\left(3,4,5\right.\right.$-triOCH$\left.{ }_{3}\right)$ $\mathrm{PP}]$ 3. Interestingly, in $p$-methoxy analogue $\mathrm{Zn}(\mathrm{T}(4-$ $\left.\mathrm{OCH}_{3}\right) \mathrm{PP}$ ), the $\mathrm{Zn}-\mathrm{O}$ bond distance is $2.69 \AA$ much longer than the $\mathrm{Zn}-\mathrm{O}$ bond distance of complex $\mathbf{1}$ and 3. ${ }^{23}$ This indicates that the metal oxygen interaction through para position is very weak. In an another work, we recently reported that metal zinc in complex $\mathbf{3}$ in the acetone-dichloromethane-water medium does not bind to methoxy oxygen of adjacent porphyrin instead binds with a water molecule. Similarly, it is reported that compound 2 binds to the water molecule in the phenolwater solvent system instead of the oxygen atom of the methoxy group.

\subsection{Synthetic aspects, electronic spectra of complexes}

The metal Zn was inserted into the tetra meta-methoxyphenylporphyrin, $\left[\mathrm{T}\left(m-\mathrm{OCH}_{3}\right) \mathrm{PP}\right]$ following known procedure $^{29}$ in DMF medium using $\mathrm{ZnCl}_{2}$ as salt and was purified by using column chromatography. The suitable crystal for diffraction was found from chloroform and petroleum ether mixture. The UV-visible spectrum of the compound 1 shows a typical Soret band at $423 \mathrm{~nm}$

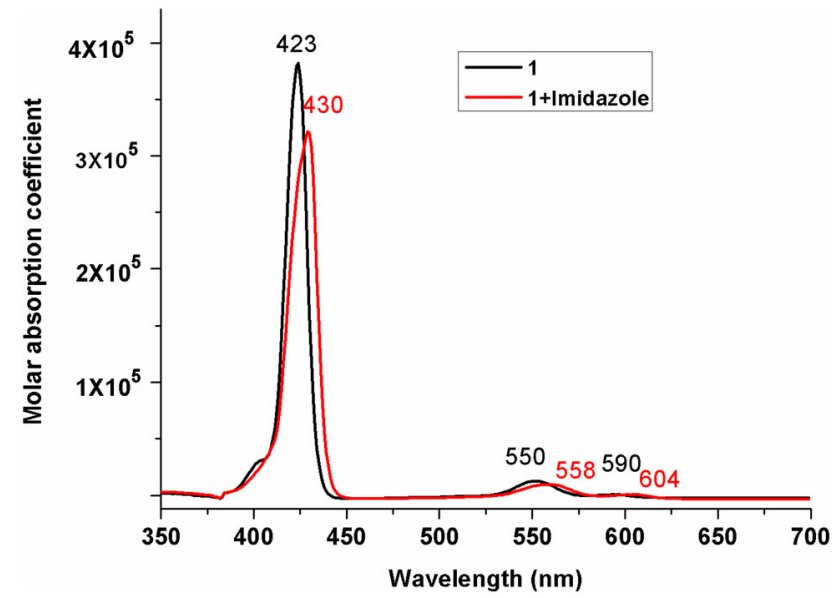

Figure 4. Electronic spectral change of compound 1 (in chloroform) upon addition of $2.0 \times 10^{-5} \mathrm{M}$ imidazole.

and Q band in the range 550-600 $\mathrm{nm}$ due to well-known porphyrin $\pi-\pi^{*}$ electronic transition. ${ }^{30}$ To understand the stability of the 1-D weak structure of complex $\mathbf{1}$, we have studied the reaction of compound 1 with some nucleophilic ligands like imidazole. The change of electronic spectra of compound $\mathbf{1}$ on the addition of imidazole is shown in Figure 4. On addition of imidazole, a red shifting of the Soret and Q band was observed indicting the binding of imidazole. ${ }^{31}$

The change in the electronic spectrum of $\mathbf{1}$ with the addition of imidazole in chloroform medium is 
consistent with previously reported results. ${ }^{31-33}$ The coordination of zinc porphyrin with imidazole and pyridine ligand has been widely studied and it is reported that zinc pentacoordinate is the usual binding mode in solution except in some cases due to chelate effect. ${ }^{32,33}$ Iron complexes of isoporphyrin (a tautomer of porphyrin) undergo ring opening in the presence of nucleophiles. ${ }^{34}$ Similarly on the addition of ethanol the electronic spectrum changes, which is due to the coordination of ethanol as an axial ligand which resists the formation of $\mathrm{Zn}-\mathrm{O}\left(\mathrm{OCH}_{3}\right)$ bond. Furthermore, we have performed solid state UV-Visible spectral studies of different zinc methoxyphenylporphyrins 1, 2, and 3 (Table 1). The Soret band for all the studied porphyrins were observed at around $420 \mathrm{~nm}$. The intensity of the Soret band for all the porphyrins was observed to be decreased in the solid state as compared to the solution.

The number of Q bands in the solid-state spectrum is the same as in the solution state spectrum (Table 1). The solid-state UV-Visible spectra of 4-bromo-2,6-bis[5-(4iminophenyl)-10,15,20-triphenylporphyrin]phenol and its metal complex are known. Authors observed fewer numbers of $\mathrm{Q}$ bands in the solid state than in the solution state. ${ }^{35}$ The solid-state UV-Visible spectrum of the compound $\mathbf{1}$ is shown in Figure S3 in Supplementary Information. The IR spectroscopy can provide some information about the structure of metalloporphyrins. The IR spectra of the free base porphyrin and compound $\mathbf{1}$ are given in Figures S4 and S5 in Supplementary Information. The bands observed in the IR spectrum of $\mathbf{1}$ agree well with those of similar compounds reported in the literature. ${ }^{36,37}$ For example, in the IR spectrum of compound 1, aromatic $v(\mathrm{C}-\mathrm{H})$ vibrates at $2928 \mathrm{~cm}^{-1}, v(\mathrm{C}-\mathrm{N})$ at 1328 $\mathrm{cm}^{-1}, \nu(\mathrm{C}=\mathrm{C})$ at $1649 \mathrm{~cm}^{-1}, v(\mathrm{C}=\mathrm{N})$ at $1587 \mathrm{~cm}^{-1}$, and methoxy group at the meta-position vibrates at $2840 \mathrm{~cm}^{-1}$ for $\nu(\mathrm{C}-\mathrm{H}), 1007 \mathrm{~cm}^{-1}$ for $\nu(\mathrm{C}-\mathrm{O}-\mathrm{C}) \mathrm{sym}$, respectively.

\subsection{Fluorescence properties and DSC studies of compound 1}

The luminescence spectra of compounds 1, 2 and $\mathbf{3}$ measured at excitation wavelength $\lambda_{\mathrm{ex}}=420 \mathrm{~nm}$ are shown in Figure 5. The luminescence spectra of the synthesized zinc methoxyphenylporphyrins are similar with the luminescence spectrum of ZnTPP (Figure 5). Fluorescence maximum of the synthesized zinc methoxyphenylporphyrin $\mathbf{1}$ and $\mathbf{2}$ was localized at $660 \mathrm{~nm}$ and a slightly weaker maximum was observed at $620 \mathrm{~nm}$ at a dilute solution $\left(10^{-6} \mathrm{M}\right)$. Compound 2 displays emission maximum at $612 \mathrm{~nm}$ and a weaker

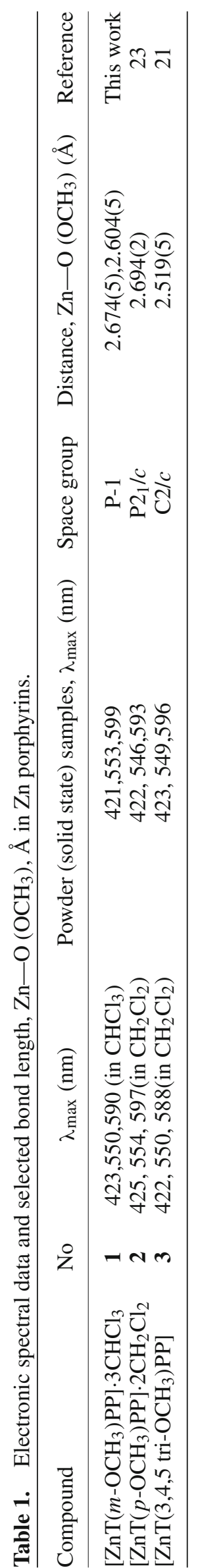




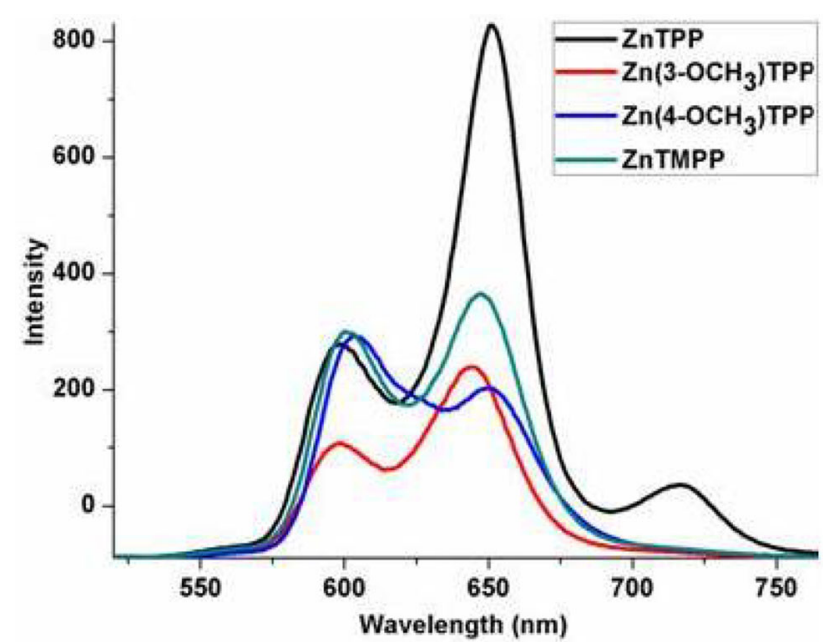

Figure 5. Luminescence spectra of compound 1, 2, 3 and ZnTPP in DCM $\left(10^{-6} \mathrm{M}\right)$. Excitation wavelength, $\lambda_{\mathrm{ex}}=420 \mathrm{~nm}$.

maximum at $665 \mathrm{~nm}$ in dilute solution $\left(10^{-6} \mathrm{M}\right)$. In concentrated solution, porphyrin emission is remarkably decreased due to the known $\pi-\pi$ stacking. ${ }^{38}$ The luminescence properties of magnesium analogue of compound $\mathbf{3}$ is known. ${ }^{39}$

The thermal studies of several porphyrins are known. ${ }^{40,41}$ We have performed the differential scanning calorimetric studies for the compound $\mathbf{l}$ at a scan rate of $5^{\circ} \mathrm{C} / \mathrm{min}$ up to $250{ }^{\circ} \mathrm{C}$. At that rate, the compound 1 showed one weak endothermic peak at onset temperature $136^{\circ} \mathrm{C}$ (Figure S6, Supplementary Information). The endothermic peak at $136^{\circ} \mathrm{C}$ is most probably due to loss of solvent chloroform molecules as for the heated sample (at $130^{\circ} \mathrm{C}$ for $2 \mathrm{~h}$ ) we did not observe any significant peak in that region.

\subsection{Theoretical calculations}

To understand the reason behind the formation of a coordination chain through the preferred meta-methoxy group we have performed the theoretical calculations using the Gaussian 03 package. ${ }^{42}$ The frontier MOs of the compound $\mathbf{1}$ with their energy is shown in Figure 6 and of compound $\mathbf{3}$ is shown in Figure S7 (Supplementary Information). The energy difference between HOMO and HOMO-1 is $0.126 \mathrm{eV}$ and the LUMO and LUMO+1 MOs is $0.265 \mathrm{eV}$. The HOMOLUMO gap is $6.41 \mathrm{eV}$. The HOMO-2 orbital has distinct contributions from $m$-methoxy oxygen atom. The Mulliken charge of compound $\mathbf{3}$ is shown in Figure S8 (Supplementary Information). The Mulliken charge of meta-methoxy oxygen atom is more negative than the para-methoxy oxygen atom (Figure S8, Supplementary Information). This result suggests that
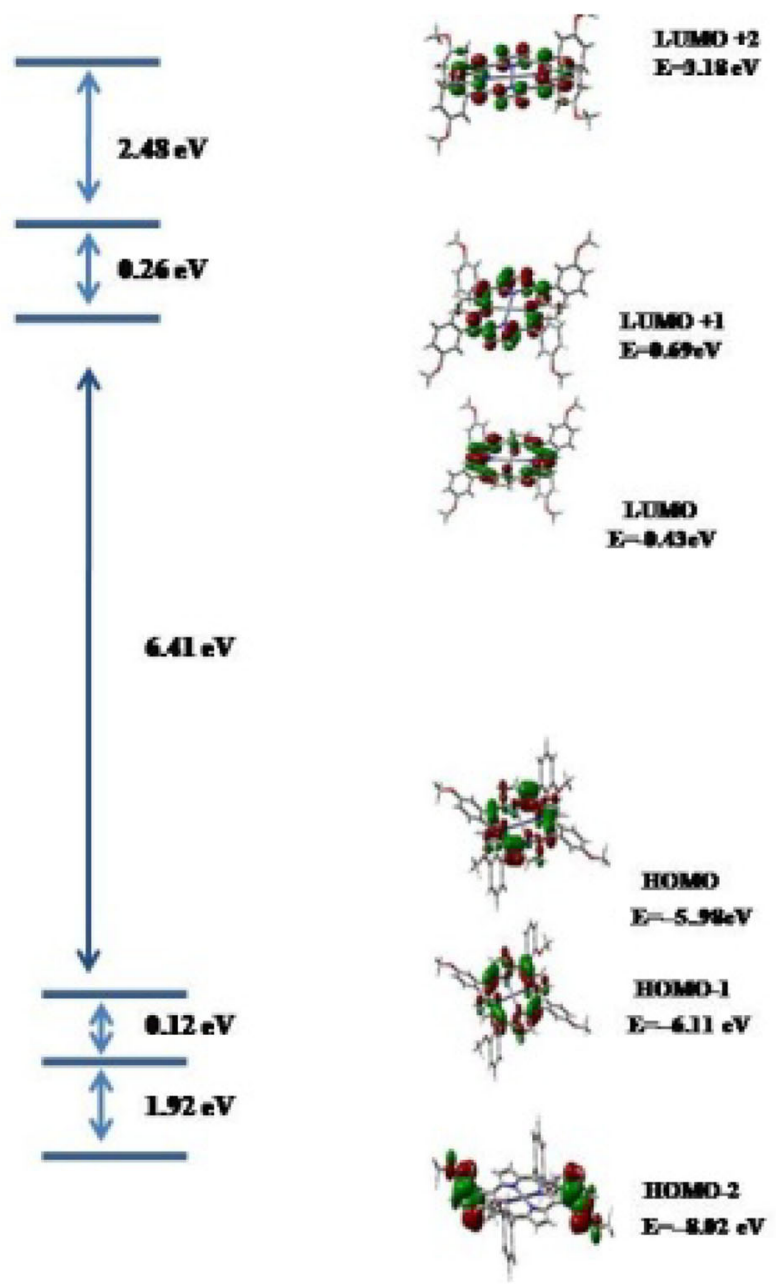

Figure 6. Frontier molecular orbital energy level diagram of compound $\mathbf{1}$.

the meta-methoxy oxygen has a higher probability of binding to the metal than the para-methoxy oxygen.

\section{Conclusions}

The complex Zn(II) 5,10,15,20-tetrakis(meta-methoxyoxyphenyl)porphyrin, 1 shows one-dimensional chain structure through secondary interaction (albeit weak) of zinc with oxygen atoms of a meta-methoxy group of the neighbouring porphyrins. The zinc-oxygen interaction observed in compound $\mathbf{1}$ is found to be stronger than similar interaction present in the compound $[\mathrm{ZnT}(p$ $\left.\left.\mathrm{OCH}_{3}\right) \mathrm{PP}\right] \mathbf{2}, p$-analogue of compound $\mathbf{1}$, but weaker than similar interaction present compound $[\mathrm{ZnT}(3,4,5-$ triOCH$\left.\left.{ }_{3}\right) \mathrm{PP}\right]$ 3. The theoretical calculation at the DFT level corroborates the higher probability of the binding of meta-methoxy oxygen than the para-methoxy oxygen to the metal in $\mathrm{Zn}$-methoxyphenyl porphyrins. Nucleophilic solvents or nucleophiles resist the formation of this weak $\mathrm{Zn}-\mathrm{O}\left(\mathrm{OCH}_{3}\right)$ bond and forms nucleophiles coordinated compounds. 


\section{Supplementary Information (SI)}

CCDC 1817617 contains the supplementary crystallographic data for complex 1. This data can be obtained free of charge from the Cambridge Crystallographic Data Centre via www.ccdc.cam.ac.uk/data_request/cif. The synthesis of compounds 1, 2 and 3, UV-Visible, fluorescence, IR spectra, and DSC spectrum are available as Supplementary Information for this article at www.ias.ac.in/chemsci.

\section{Acknowledgements}

JB acknowledges SERB, DST, New Delhi for funding (YSS/2015/000394). Authors thank Dr. Md. Harunar Rashid, Department of Chemistry, Rajiv Gandhi University, Itanagar for allowing to use the fluorescence spectrophotometer.

\section{References}

1. Huaping L, Bing Z, Yi L, Lingrong G, Wei W, Fernando K A S, Kumar S, Lawrence F A and Sun Y P 2004 Selective interactions of porphyrins with semiconducting single-walled carbon nanotubes J. Am. Chem. Soc. 1261014

2. Urbanova M, Setnic V, Kral V and Volka K 2001 Noncovalent interactions of peptides with porphyrins in aqueous solution: conformational study using vibrational CD spectroscopy J. Pept. Sci. 60307

3. Murakami H, Nomura T and Nakashima N 2003 Noncovalent porphyrin-functionalized single-walled carbon nanotubes in solution and the formation of porphyrinnanotube nanocomposites Chem. Phys. Lett. 378481

4. Cheng F, Zhang S, Adronov A, Echegoyen L and Diederich F 2006 Triply fused $\mathrm{Zn}^{I I}$-porphyrin oligomers: synthesis, properties, and supramolecular interactions with single-walled carbon nanotubes (swnts) Chem. Eur. J. 126062

5. Titi H M, Tripuramallu B K and Goldberg I 2016 Porphyrin-based assemblies directed by non-covalent interactions highlights of recent investigations CrystEngComm 183318

6. Stangel C, Charisiadis A, Zervaki G E, Nikolaou V, Charalambidis G, Kahnt A, Rotas G, Tagmatarchis N and Coutsolelos G A 2017 A case study for artificial photosynthesis: non-covalent interactions between $\mathrm{C}_{60}$ dipyridyl and zinc porphyrin dimer J. Phys. Chem. 121 4850

7. Borah K D and Bhuyan J 2017 Magnesium porphyrins with relevance to chlorophylls Dalton Trans. 466497

8. Hayashi T and Ogoshi H 1997 Molecular modelling of electron transfer systems by noncovalently linked porphyrin-acceptor pairing Chem. Soc. Rev. 26355

9. Lang K, Mosinger J and Wagnerov D M 2004 Photophysical properties of porphyrinoid sensitizers noncovalently bound to host molecules; models for photodynamic therapy Coord. Chem. Rev. 248321

10. Bhuyan J and Sarkar S 2012 Nitrous acid mediated synthesis of iron-nitrosyl-porphyrin: $\mathrm{pH}$-dependent release of nitric oxide Chem. Asian J. 72690
11. Batten S R, Champness N R, Chen X, Martinez J G, Kitagawa S, Ohrstrom L, O'Keeffe M, Suhh M P and Reedijk J 2012 Coordination polymers, metal-organic frameworks and the need for terminology guidelines CrystEngComm 143001

12. Huh S, Kim S J and Kim Y 2016 Porphyrinic metalorganic frameworks from custom-designed Porphyrins CrystEngComm 18345

13. Gao W Y, Chrzanowski M and Ma S 2014 Metalmetalloporphyrin frameworks: a resurging class of functional materials Chem. Soc. Rev. 435841

14. Lipstman S and Goldberg I 2010 Porphyrin framework solids. Hybrid supramolecular assembly modes of tetrapyridylporphyrin and aqua nitrates of lanthanoid ions Cryst.Growth Des. 101823

15. Johnson J A, Lin Q, Wu L C, Obaidi N, Olson Z L, Reeson R T, Chen Y S and Zhang J 2013 A "pillar-free", highly porous metalloporphyrinic framework exhibiting eclipsed porphyrin arrays Chem. Comm. 492828

16. Sun W, Wang H, Qi D, Wang L, Wang K, Kan J, Li W, Chen Y and Jiang J 2012 5,10,15,20-tetra(4pyridyl)porphyrinato zinc coordination polymeric particles with different shapes and luminescent properties CrystEngComm 147780

17. Krupitsky H, Stein Z and Goldberg I 1994 Crystalline complexes, coordination polymers and aggregation modes of tetra(4-pyridyl)porphyrin J. Incl. Phenom. Macrocycl. Chem. 18177

18. Shmilovits M, Vinodu M and Goldberg I 2004 Coordination polymers of tetra(4 carboxyphenyl)porphyrins sustained by tetrahedral zinc ion linkers Cryst. Growth Des. 4633

19. Teo T L, Vetrichelvan M and Lai Y H 2003 Infinite three-dimensional polymeric metalloporphyrin network via six-coordinate $\mathrm{Zn}$ (II) and two axial oxygen donors Org. Lett. 54207

20. Ikbal S, Brahma S, Dhamija A and Rath S P 2014 Building-up novel coordination polymer with Zn(II) porphyrin dimer: Synthesis, structures, surface morphology and effect of axial ligands J. Chem. Sci. 1261451

21. Bhuyan J and Sarkar S 2011 Self-assembly of magnesium and zinc trimethoxyphenylporphyrin polymer as nanospheres and nanorods Cryst. Growth Des. 115410

22. Saleh R Y and Straub D K 1989 13C NMR spectra of tetra(3,4,5-trimethoxyphenyl)porphyrin and its zinc and iron(III) complexes Inorg. Chim. Acta 1569

23. McGill S, Nesterov V N and Gould S L 2013 [5,10,15,20Tetra-kis(4-methoxyphenyl)porphyrinato]zinc dichloromethane disolvate Acta Cryst. $69 \mathrm{~m} 471$

24. Okada S and Segawa H 2003 Substituent-control exciton in j-aggregates of protonated water-insoluble porphyrins J. Am. Chem. Soc. 1252792

25. Wei X, Du X, Chen D and Chen Z 2006 Thermal analysis study of 5,10,15,20-tetrakis (methoxyphenyl)porphyrins and their nickel complexes Thermochim. Acta $\mathbf{4 4 0}$ 181

26. Dolomanov O V, Bourhis L J, Gildea R J, Howard J A K and Puschmann H 2009 Complete structure solution, refinement and analysis program J. Appl. Cryst. 42339

27. Adler A D, Longo F R, Finarelli J D, Goldmacher J, Assour J and Korsakoff L 1967 A simplified synthesis for meso-tetraphenylporphine J. Org. Chem. 32476 
28. Goldberg I, Krupitsky H, Stein Z, Hsiou Y and Strouse E C 1994 Supramolecular architectures of functionalized tetraphenylmetalloporphyrins in crystalline solids. Studies of the 4-methoxyphenyl, 4-hydroxyphenyl and 4-chlorophenyl derivatives Supramol. Chem. 4 203

29. Barnnet G H, Hudson M F and Smith K M 1975 Concerning meso-tetraphenylporphyrin purification $J$. Chem. Soc. 141401

30. Gouterman M 1961 Spectra of Porphyrins J. Mol. Spectrosc. 6138

31. Zaitzeva S V, Zdanovich S A, Ageeva T A, Ocheretovi A S and Golubchikov O A 2000 Influence of the nature of porphyrin and extraligand on the stability of zinc extracomplexes Molecules 5786

32. Favereau L, Cnossen A, Kelber J B, Gong J Q, Oetterli R M, Cremers J, Herz L M and Anderson $\mathrm{H}$ L 2015 Six-coordinate zinc porphyrins for templatedirected synthesis of spiro-fused nanorings $J$. Am. Chem. Soc. 13714256

33. Wang S, Peng U, Zhang C, Li Y and Liu C 2016 Synthesis of zinc porphyrn and effect of peripheral substituent on the coordination reaction Indian J. Chem. 55145

34. Bhuyan J 2016 Nucleophilic ring-opening of iron(III)hydroxyisoporphyrin Dalton Trans. 452694

35. Tumer M, Gungor S A and Çiftaslan A R 2016 Solid state and solution photoluminescence properties of a novel meso-meso-linked porphyrin dimer schiff base ligand and its metal complexes J. Lumin. 170108

36. Boucher L J and Katz J J 1967 The infared spectra of metalloporphyrins (4000-160 $\left.\mathrm{cm}^{-1}\right) \mathrm{J}$. Am. Chem. Soc. 89 1340

37. Filip A G, Clichici S, Daicoviciu D, Ion R M, Tatomir C, Rogojan L, Opris I, Mocan T, Olteanu D and Muresan A 2011 Possible in vivo mechanisms involved in photodynamic therapy using tetrapyrrolic macrocycles $\mathrm{Braz}$. J. Med. Biol. Res. 4453
38. Takashima H, Fujimoto E, Hirai C and Tsukahara K 2008 Synthesis and spectroscopic properties of reconstituted zinc-myoglobin appending a DNA-binding platinum(II) complex Chem. Biodivers. 52101

39. Borah K D, Singh N G and Bhuyan J 2017 Magnesium trimethoxyphenylporphyrin chain controls energy dissipation in the presence of cholesterol J. Chem. Sci. 129 449

40. Guan C, Li I, Chen D, Gao Z and Sun W 2002 Thermal behavior and thermal decomposition study of porphyrin polymers containing different spacer groups Thermochim. Acta $\mathbf{4 1 3} 31$

41. Medforth C J, Haddad R E, Muzzi C M, Dooley N R, Jaquinod L, Shyr D C, Nurco D J, Olmstead M M, Smith K M, Ma J G and Shelnutt J A 2003 Unusual arylporphyrin rotational barriers in peripherally crowded porphyrins Inorg. Chem. $\mathbf{4 2} 2227$

42. Frisch M J, Trucks G W, Schlegel H B, Scuseria G E, Robb M A, Cheeseman J R, Montgomery Jr J A., Vreven T, Kudin K N, Burant J C, Millam J M, Iyengar S S, Tomasi J, Barone V, Mennucci B,Cossi M, Scalmani G, Rega N, Petersson G A, Nakatsuji H, Hada M, Ehara M, Toyota K, Fukuda R, Hasegawa J, Ishida M, Nakajima T, Honda Y, Kitao O, Nakai H, Klene M, Li X, Knox J E, Hratchian H P, Cross J B, Bakken V, Adamo C, Jaramillo J,Gomperts R, Stratmann R E, Yazyev O, Austin AJ, Cammi R, Pomelli C, Ochterski J W, Ayala P Y, Morokuma K, Voth G A, Salvador P, Dannenberg J J, Zakrzewski V G, Dapprich S, Daniels A D, Strain M C, Farkas O, Malick D K, RabuckA D, Raghavachari K, Foresman J B, Ortiz J V, Cui Q, Baboul A G, Clifford S, Cioslowski J, Stefanov B B, Liu G, Liashenko A, Piskorz P, Komaromi I, Martin R L, Fox D J, Keith T, Al-Laham M A, Peng C Y, Nanayakkara A, Challacombe M, Gill P M W, Johnson B, Chen W, Wong M W, Gonzalez C and Pople J A Gaussian 03 (Revision B.05), Gaussian 03, Revision B.04, Gaussian Inc., Pittsburgh, P A, 2003 